\title{
Detection of buffalo milk adulteration with cow milk by capillary electrophoresis analysis
}

\author{
Francesca Trimboli, ${ }^{*}$ Nicola Costanzo, Vincenzo Lopreiato, Carlotta Ceniti, Valeria M. Morittu, \\ Antonella Spina, and Domenico Britti \\ Department of Health Science, Magna Græcia University, Viale Europa, loc. Germaneto, 88100, Catanzaro, Italy
}

\section{ABSTRACT}

The addition of cow milk during the production of buffalo mozzarella is a common fraud in dairy industries because of the lower price and greater availability of cow milk throughout the year. The aim of this study was to develop a new, rapid, and robust capillary electrophoresis method for detecting and quantifying cow milk in buffalo milk by exploiting cow $\alpha$-lactalbumin as a marker of adulteration. In particular, a linear calibration curve was generated, using a training set of calibrators consisting of 7 series of 17 buffalo/bovine whey mixtures, obtained after casein precipitation, with increasing percentages of cow whey. The capillary electrophoresis method showed high linearity $\left(\mathrm{R}^{2}\right.$ $=0.968)$, repeatability [relative standard deviation $(\mathrm{RSD})=2.11,3.02,4.38$, and $1.18 \%$, respectively for 5 , 10,20 , and $50 \%$ of buffalo/bovine whey mixtures], and intermediate precision $(\mathrm{RSD}=2.18,2.49,5.09$, and $3.19 \%$, respectively, for $5,10,20$, and $50 \%$ buffalo/bovine whey mixtures). Moreover, the minimum amount of detectable fraudulent cow milk was $1 \%$, and the limit of quantification was $3.1 \%$.

Key words: buffalo, cow, milk adulteration, capillary electrophoresis

\section{INTRODUCTION}

In Italy, buffalo milk and its derivatives have great economic relevance, especially in central-southern regions where farming is a primary economic activity. Therefore, defending the quality of products, such as buffalo mozzarella or pecorino cheese, is very important. This importance is underscored by the European Union attaching a legal trademark, known as the pro-

Received December 21, 2018.

Accepted March 14, 2019.

*Corresponding author: trimboli@unicz.it tected designation of origin (PDO; European Union, 2008a), to food with quality characteristics, based on both natural and human factors, that essentially or exclusively depend on the territory where they were produced.

The most common fraud in the production of Mozzarella di Bufala Campana PDO (buffalo mozzarella) is the addition of cow milk, which qualitatively differs from buffalo milk, has a lower price, and is available throughout the year (Borková and Snášelová, 2005). The addition of cow milk negatively affects the quality of the final products, not only changing their organoleptic properties but also representing a food safety concern for individuals with a cow milk intolerance or allergy (Zachar et al., 2011).

Through the years, the dairy industry has continuously collaborated with research investigators to develop and apply a quick and efficient method for routine use to detect possible fraudulent addition of cow milk to goat, ewe, or buffalo milk.

The official method to detect the presence of cow milk in ewe, goat, and buffalo milks is the isoelectric focusing of $\gamma$-caseins after plasminolysis (European Union, 2008b). This method is based on comparison with the protein patterns of certified reference standards, and it enables qualitative estimation of cow milk in tested samples.

Many analytical methods have been developed to identify the illegal addition of bovine milk to buffalo milk and mozzarella cheese. Recently, Dal Bosco et al. (2018) developed a novel approach based on the use of species-specific low-molecular-weight biomarkers of cow milk (in particular $\beta$-carotene, lutein, and $\beta$-cryptoxanthin) quantified by liquid chromatographytandem mass spectrometry analyses. Other methods are based on PCR, including real-time PCR assay, and exploit species-specific DNA sequences to distinguish cow DNA in milk and mozzarella from water buffalo DNA (Dalmasso et al., 2011; Di Domenico et al., 2017; Hazra et al., 2017). Overall, most analytical methods are focused on the proteomic evaluation of buffalo milk 
and its derivatives using chromatography (Enne et al., 2005; Cerquaglia et al., 2011) and mass spectrometry (Czerwenka et al., 2010; Sassi et al., 2015; Chen et al., 2016).

The application of capillary electrophoresis $(\mathbf{C E})$ has clearly demonstrated an ability to separate, identify, and quantify the principal milk proteins (Cartoni et al., 1999; Molina et al., 1999; Rodriguez-Nogales, 2006; Trimboli et al., 2017). Molina et al. (1999) demonstrated that $\mathrm{CE}$ could provide clearly distinct capillary electrophoretic profiles of casein fractions from $100 \%$ cow, ewe, and goat milks that were useful to predict the species of the milk in mixtures. Capillary electrophoresis also proved to be a valid method to recognize the presence of cow milk in goat milk and cheese, with a $2 \%$ detection limit of cow milk, by exploiting the cow $\beta$-LG variant $B(\boldsymbol{\beta}-\mathbf{L G B})$ and goat $\alpha$-LA ratio to develop a robust calibration curve (Cartoni et al. 1999). Rodriguez-Nogales (2006) applied multivariate calibration methods, such as partial least square regression and principal component regression, to $\mathrm{CE}$ electropherograms of cow, ewe, and goat casein fractions, developing a good prediction model for percentages of the milk of each species. Moreover, Trimboli et al. (2017) proposed a rapid $\mathrm{CE}$ approach that allows a quick and inexpensive recognition of ewe milk in cow milk with good performance. The use of the CE method coupled with mass spectrometry exploiting the 2 variants $\mathrm{A}$ and $\mathrm{B}$ of cow $\beta-\mathrm{LG}$ as markers was also proposed for monitoring milk adulteration (Muller et al., 2008).

Nevertheless, to our knowledge, only 1 work has described the use of $\mathrm{CE}$ as a tool to determine the presence of cow milk in products labeled "pure domestic buffalo milk" (Cartoni et al., 1998). Cartoni et al. (1998) employed 2 cow whey proteins, $\alpha-\mathrm{LA}$ and $\beta$-LG variant $\mathrm{A}$ and $\mathrm{B}$ ( $\beta$-LGA and $\beta$-LGB), as markers of adulteration: the first is used to quantify a low amount $(\leq 25 \%)$ and the second, a high amount $(>25 \%)$ of cow milk in buffalo milk and cheese.

The aim of this work was to develop a new, rapid, and robust $\mathrm{CE}$ method for predicting the concentration of cow milk fraudulently added to buffalo milk, using only 1 marker and a CE instrument routinely used in human blood analysis.

\section{MATERIALS AND METHODS}

\section{Animals, Milk Collection, and Reagents}

Bulk tank samples of Mediterranean buffalo (Bubalus bubalis) milk were provided by 3 dairy farms located in Calabria (southern Italy), and bulk tank samples of raw cow (Bos taurus) milk were provided by 5 dairy farms with different breeds (Jersey, Holstein-Friesian, Italian Brown, Italian Simmental, and cross-breed). Milk samples were collected from October 2017 to February 2018 and were immediately delivered at $4{ }^{\circ} \mathrm{C}$ to our laboratory, divided into aliquots, and stored at $-20^{\circ} \mathrm{C}$ until analysis.

Purified cow $\alpha$-LA (product no. L6010), cow $\beta$-LGA (product no. L7880), cow $\beta$-LGB (product no. L8005), cow serum albumin (ALB, product no. A7030), and cow $\beta$-CN (product no. C6905) were obtained from Sigma Aldrich SRL (Milano, Italy).

\section{Sample Preparation for CE}

Before the analysis, milk samples were thawed overnight at $4^{\circ} \mathrm{C}$ and skim milk was obtained by centrifugation at 2,500 $\times g$ at $4^{\circ} \mathrm{C}$ for $30 \mathrm{~min}$ (Heraeus Megafuge 1.0R; Thermo Fisher, Waltham, MA). The fat layer was removed, and the skim milk was diluted 1:1 with distilled water.

Standard samples for a calibration curve were prepared by mixing buffalo skim milk with cow skim milk from 0 to $100 \%$ (vol/vol): $0,1,2.5,5,10,20,25,30,50$, $70,75,80,90,95,97.5,99$, and $100 \%$. Each buffalo skim milk sample was mixed with a skim milk sample from a single cow breed, resulting in a total of 188 milk standards. Whey from each standard sample was obtained as described in Lopreiato et al. (2017). Briefly, rennet solution (100\% chymosin; 200 international milk clotting units/mL, Hansen Standard Chy-Max Plus 200, Chr. Hansen, Hørsholm, Denmark) at a final concentration of $0.014 \%$ ( vol/vol) was added to milk samples at $37^{\circ} \mathrm{C}$ for $30 \mathrm{~min}$ to promote casein precipitation. Then, samples were centrifuged at $3,000 \times g$ for $15 \mathrm{~min}$ at $4^{\circ} \mathrm{C}$, and the collected whey was filtered using a $0.45-$ $\mu \mathrm{m}$ syringe filter (Minisart, Sartorius Stedim Biotech GmbH, Göttingen, Germany) before CE analysis.

\section{Capillary Electrophoresis Analysis}

Capillary electrophoresis analysis was carried out using a fully automated Minicap CE system (Sebia, Lisses, France) equipped with two $17-\mathrm{cm}$ (16 $\mathrm{cm}$ to detection point $) \times 25-\mu \mathrm{m}$ i.d. coated fused-silica capillaries, and a 200-nm UV detector at the cathode extremity. Whey proteins were analyzed by the Capillarys Protein(E) 6 kit (Sebia), which is designed to separate human serum and urine proteins in an alkaline buffer, according to the manufacturer's instructions. More detailed information on the CE analysis is described in Trimboli et al. (2017). 


\section{Capillary Electrophoresis Calibration and Validation}

The calibration equation to quantify the percentage of cow milk fraudulently added to buffalo milk was derived through a regression analysis of the fraction area values (\% of total curve area) relative to the cow-specific fraction in the electropherogram and percentage of cow whey in standard samples. Calibration analysis was performed using data obtained from a training set of calibrator samples consisting of 7 series of 17 buffalo/bovine mixtures, with increased percentage of cow whey $(0-100 \%)$, each prepared with independent cow and buffalo skim milk samples.

Linear model validation was performed using data obtained from a test set of samples consisting of 6 series of mixtures, each prepared with independent skim milk samples differing from those used as calibrators. Validation was performed by evaluating linearity in the range of 0 to $100 \%$ of cow whey and precision (repeatability and intermediate precision): repeatability was calculat- ed as relative standard deviation percentage (RSD \%) for 4 replicates at 4 concentrations of cow whey content $(5,10,20$, and $50 \%)$ and intermediate precision was calculated as RSD \%, for $4 \mathrm{~d}$ at 4 levels of cow whey content $(5,10,20$, and 50\%). Accuracy was evaluated by calculating the standard error of estimated (SEE) and standard deviation of residuals (Sy.x). The SEE was calculated as the difference between the average of estimated values for replicates at all levels of cow whey content and the reference value. The cow whey limit of quantification (LOQ) was calculated using the standard deviation (SD) of the blank ( $100 \%$ buffalo whey) as follows: $\mathrm{LOQ}=10 \mathrm{SD} /$ (slope of the regression line). The limit of detection (LOD) was also calculated, as follows: $\mathrm{LOD}=3 \mathrm{SD} /($ slope of the regression line).

\section{Statistical Analysis}

Mean, SD, RSD \%, and normality of residuals were performed using SAS software (Ver. 9.4, SAS Institute
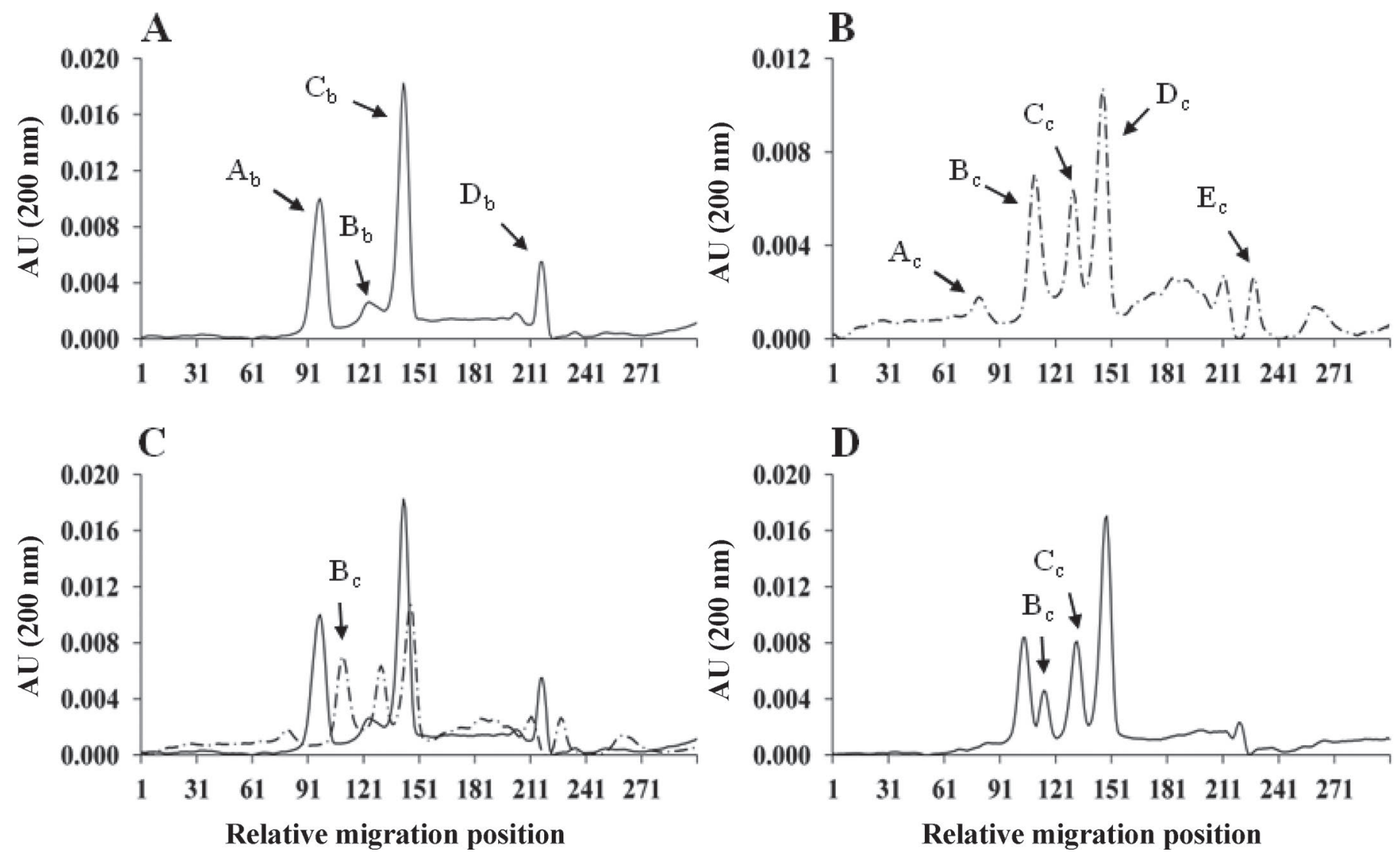

Figure 1. Capillary electrophoresis (CE) profiles of buffalo and cow whey proteins. The CE protein profiles of buffalo (A) and cow (B) whey; (C) overlay of buffalo (continuous line) and cow (dashed line) whey protein profiles; (D) representative CE protein profile of a mixture (1:1, $\mathrm{vol} / \mathrm{vol}$ ) of buffalo/bovine whey. Arrows indicate the major peaks. $\mathrm{Ab}=$ buffalo $\alpha-\mathrm{LA} ; \mathrm{Bb}=$ position occupied by purified cow $\beta$-LG variant $\mathrm{A} ; \mathrm{Cb}=$ buffalo $\beta$-LG variant $\mathrm{B} ; \mathrm{Db}=$ buffalo $\beta-\mathrm{CN} ; \mathrm{Ac}=\mathrm{cow}$ albumin; $\mathrm{Bc}=$ cow $\alpha-\mathrm{LA} ; \mathrm{Cc}=$ cow $\beta$-LG variant $\mathrm{A} ; \mathrm{Dc}=\beta-\mathrm{LG}$ variant $\mathrm{B}$; $\mathrm{Ec}=\operatorname{cow} \beta-\mathrm{CN} . \mathrm{AU}=$ absorbance units. 
Inc., Cary, NC). Regression analysis was performed using Proc REG of SAS (Ver. 9.4), and normality of residuals was evaluated by the Kolmogorov-Smirnov test.

\section{RESULTS AND DISCUSSION}

\section{Identification of a Marker of Buffalo Milk Adulteration}

Capillary electrophoresis separation of cow whey proteins resulted in a typical protein profile that was clearly distinct from the $\mathrm{CE}$ profile of buffalo whey proteins (Figures $1 \mathrm{~A}$ and $\mathrm{B}$ ). In the latter, 3 main fractions $\left(A_{b}, C_{b}\right.$, and $\left.D_{b}\right)$ and 1 minor fraction $\left(B_{b}\right)$ were present (Figure 1A). The profile of cow whey proteins also had 3 main fractions (named $\mathrm{B}_{\mathrm{c}}, \mathrm{C}_{\mathrm{c}}$, and $\mathrm{D}_{\mathrm{c}}$ ), but in contrast to the buffalo protein profile, it had 2 minor fractions $\left(A_{c}\right.$ and $E_{c}$; Figure $\left.1 B\right)$. When cow and buffalo whey protein profiles were overlaid, a specific cow fraction $\left(\mathrm{B}_{\mathrm{c}}\right)$ was clearly discernible (Figure $1 \mathrm{C}$ ). Notably, this fraction was not present in the buffalo protein profile (Figure 1C). Moreover, in analyzing the $\mathrm{CE}$ protein profile of the cow/buffalo whey mixture $(1: 1, \mathrm{vol} / \mathrm{vol})$, we confirmed that the cow fraction $\mathrm{B}_{\mathrm{c}}$ was easily recognizable (Figure $1 \mathrm{D}$ ). This result supports the possible use of cow fraction $\mathrm{B}_{\mathrm{c}}$ as a marker of buffalo milk adulteration with cow milk.

To identify the protein components of the CE electropherograms, we performed a $\mathrm{CE}$ analysis on buffalo and cow whey after the addition of single purified proteins to the whey. The identification was confirmed by an increased signal of each peak of the individual proteins added.

According to Trimboli et al. (2017), peaks $A_{c}, B_{c}$, and $\mathrm{E}_{\mathrm{c}}$ on the cow electropherogram represent ALB, $\alpha-\mathrm{LA}$, and $\beta-\mathrm{CN}$ proteins (Figure $1 \mathrm{~B}$ ), respectively. In this work, we confirm that the $B_{c}$ peak of the cow whey protein profile (Figure 1B) was related to $\alpha$-LA, as evidenced by the increase in peak signal (Figure 2A). When purified $\alpha$-LA was added to buffalo whey, a new peak $\left(\mathrm{A}_{\mathrm{b}}\right)$ appeared on the electropherogram (Figure $3 \mathrm{~A})$, occupying the same position of peak $\mathrm{B}_{\mathrm{c}}$ on the cow electropherogram (Figure 1B). We postulate that buffalo peak $A_{b}$ corresponds to $\alpha-L A$ and the different electrophoretic mobility between bovine and buffalo $\alpha$-LA depends on differences in their biochemical properties. Moreover, differential separation of cow and buffalo $\alpha-\mathrm{LA}$ in $\mathrm{CE}$ was also reported by Cartoni et al. (1998).

The peaks on the cow whey electropherogram corresponding to $\beta$-LGA and $\beta$-LGB were identified by increases in peaks $\mathrm{C}_{\mathrm{c}}$ and $\mathrm{D}_{\mathrm{c}}$, respectively (Figures $2 \mathrm{~B}$ and $\mathrm{C}$ ). Addition of purified $\beta$-LGA and $\beta$-LGB proteins to buffalo whey led to increases of peaks $B_{b}$ and $\mathrm{C}_{\mathrm{b}}$, respectively (Figures $3 \mathrm{~B}$ and $\mathrm{C}$ ). Finally, the buffalo peak $\mathrm{D}_{\mathrm{b}}$ (Figure 1A) corresponded to $\beta-\mathrm{CN}$ as suggested by its increase (Figure 3D).

We verified the precision of the relative migration position of cow fraction $\mathrm{B}_{\mathrm{c}}$ on the $\mathrm{CE}$ electropherogram by running $4 \mathrm{cow} /$ buffalo mixtures with increasing quantities of cow milk $(5,10,20$, and $50 \%)$. The cow fraction $\mathrm{B}_{\mathrm{c}}$ migration zone was defined by its initial $\left(\boldsymbol{x}_{\mathrm{i}}\right)$ and final $\left(\boldsymbol{x}_{\mathrm{f}}\right)$ position value on the $x$-axis of the electropherogram. As shown in Table 1 , the cow fraction $B_{c}$
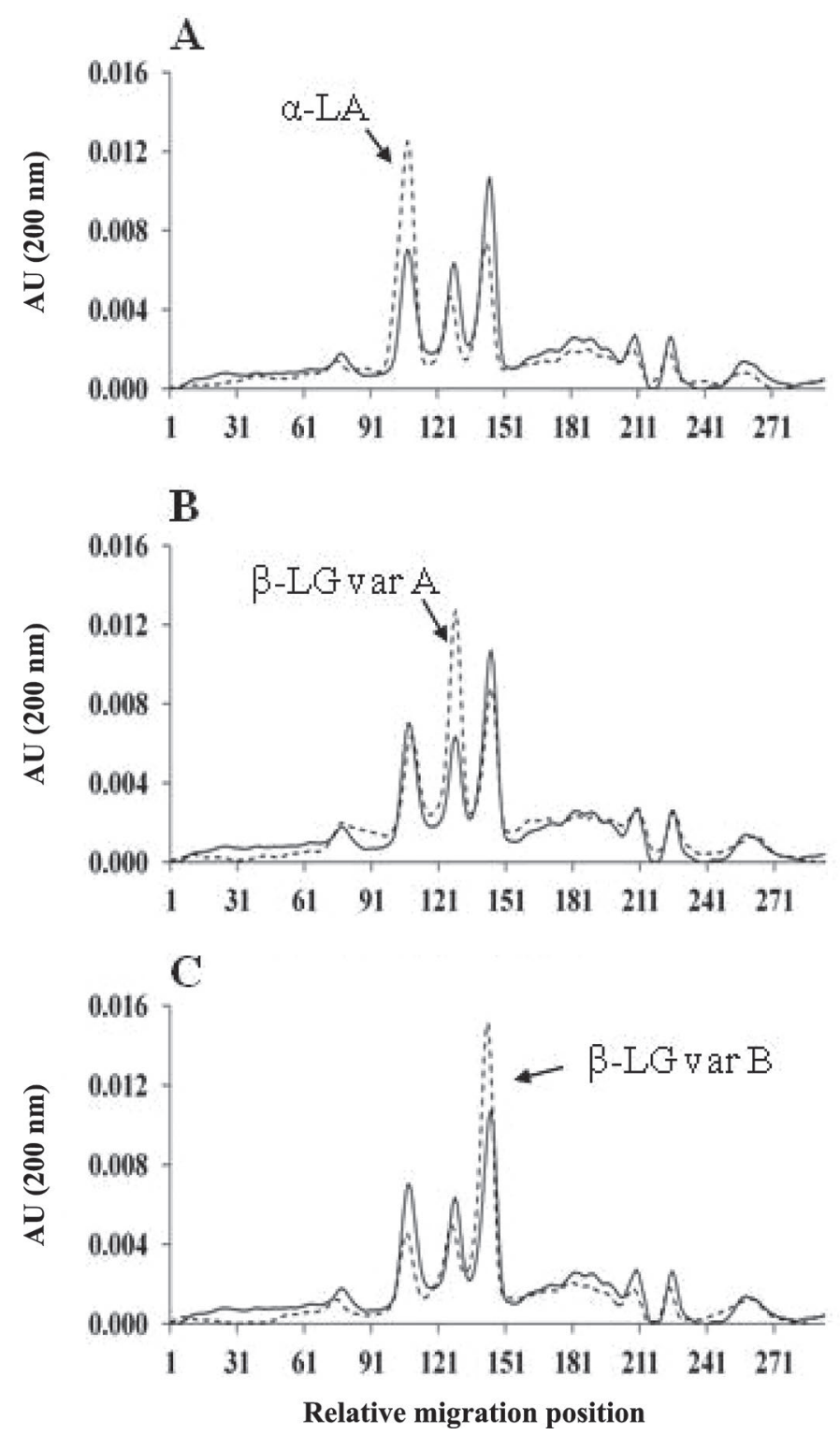

Figure 2. Identification of proteins generating peaks on a cow whey electropherogram from capillary electrophoresis (CE). Identification of the (A) $\alpha-L A$ peak, (B) $\beta-L G$ variant $A$, and (C) $\beta-L G$ variant B. Electropherograms of whey proteins without addition of purified proteins are indicated by continuous lines; dashed lines indicate electropherograms with the addition of purified proteins to whey. $\mathrm{AU}=$ absorbance units. 
migration zone had a low $x_{\mathrm{i}}$ and $x_{\mathrm{f}} \mathrm{RSD} \%$, confirming its high repeatability and intermediate precision. The high repeatability and intermediate precision of the $\mathrm{B}_{\mathrm{c}}$ fraction migration zone of our $\mathrm{CE}$ can be exploited to detect the possible existence of $\alpha$-LA variants having a different mobility in electrophoresis, which could negatively affect its use as a milk adulteration marker.

\section{Development of a Calibration Equation to Quantify Cow Milk in Buffalo Milk}

Seven training sets of calibrator samples (see "Sample preparation for CE" in Materials and Methods), with increasing percentages of cow milk from 0 to $100 \%$ and prepared with independent buffalo and cow bulk milk samples, were employed to calculate the percentage area of the cow fraction $B_{c}(\alpha-L A)$. We found the existence of a linear relationship between the percentage area of $\alpha-\mathrm{LA}$ and the percentage of cow milk in calibrator samples. As shown in Table 2, each set of training values obtained yielded approximately a straight line with a coefficient of determination $\left(\mathrm{R}^{2}\right)$ ranging from
0.971 to 0.988 . Collectively, the sets resulted in the following calibration equation: $\%$ cow milk $=9.1 \times$ (peak area $\mathrm{B}_{\mathrm{c}}$ ) -16.9 (standard deviation $=6.85 ; 95 \% \mathrm{CI}$ $y$-intercept $=-19.5$ to $-14.4 ; 95 \%$ CI slope $=8.8$ to $\left.9.5, \mathrm{R}^{2}=0.968\right)$ (Table 2, $\mathrm{C} 1-\mathrm{C} 7$ data set). Moreover, in support of the linearity of our regression model, each training set showed a normal distribution of residuals (Table 2). The LOQ of our calibration model was estimated to be $3.4 \%$ of cow milk, whereas the LOD, the lowest concentration of cow whey that could be detected but not necessarily determined quantitatively, was $1 \%$. The LOQ found in the current study was lower than that described by Cartoni et al. (1998) but comparable to the LOQ found with other methodologies (Caira et al., 2016; Dal Bosco et al., 2018), indicating the good performance of the CE method.

Moreover, as shown in Table 3 the percentage area of cow $\alpha$-LA at all cow milk levels tested confirmed good CE repeatability and intermediate precision (Table 3).

These results corroborate the ability and reliability of our CE method to directly identify the presence of cow milk that is fraudulently added to buffalo milk, even at
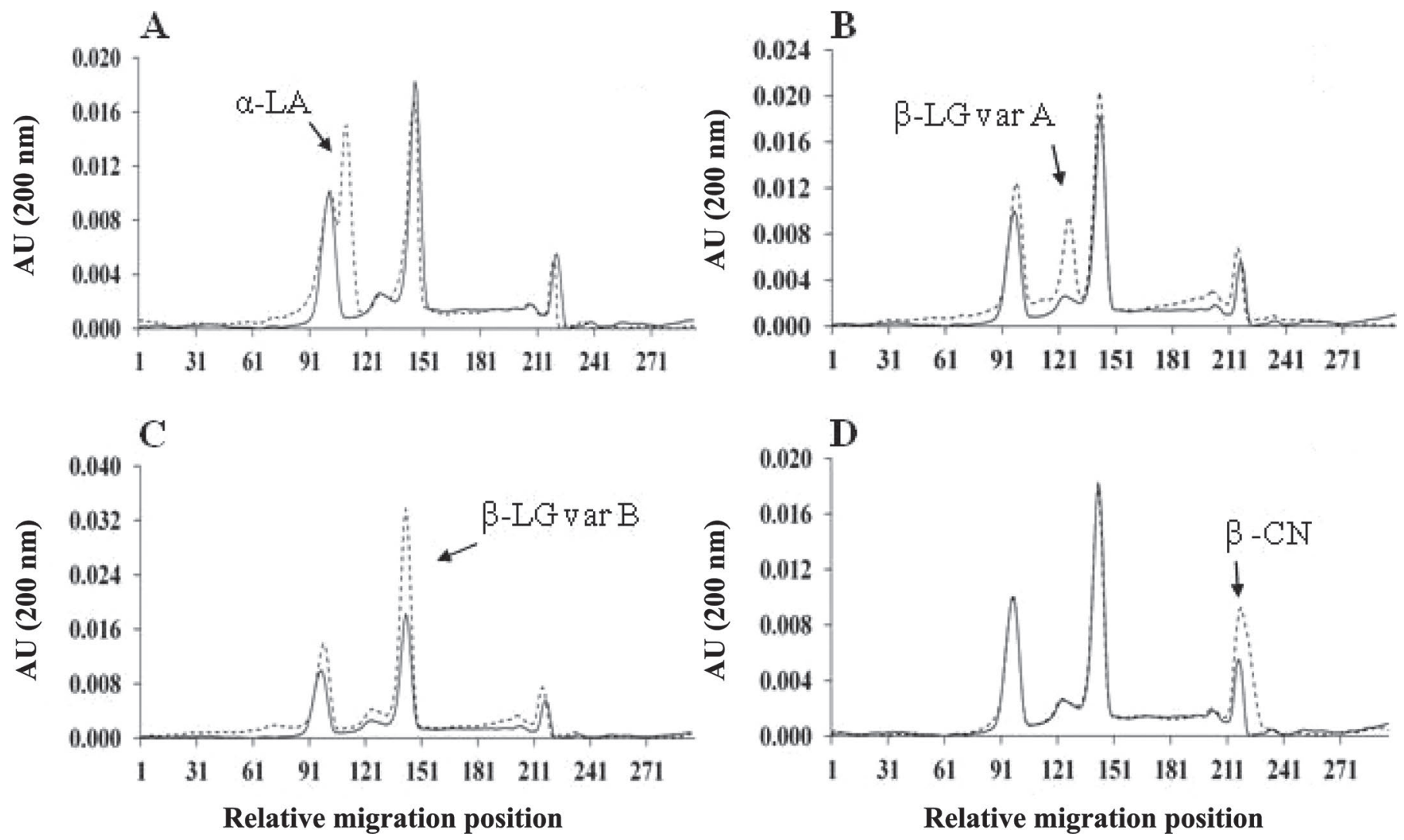

Figure 3. Identification of proteins generating peaks on capillary electrophoresis (CE) buffalo whey electropherogram. Identification of the (A) $\alpha$-LA peak, (B) $\beta$-LG variant A, (C) $\beta$-LG variant B, and (D) $\beta$-CN. Electropherograms of whey proteins without the addition of purified proteins are indicated by continuous lines; dashed lines indicate electropherograms with the addition of purified proteins to whey. AU $=$ absorbance units. 
a low concentration. Our CE approach employs only 1 cow protein as the adulteration marker for the whole percentage interval of cow milk in buffalo milk tested. In contrast, the $\mathrm{CE}$ method proposed by Cartoni et al. (1998) used 4 proteins for the same purpose, the cow $\beta$-LGA $/ \beta$-LGB ratio and $\alpha-\mathrm{LA}_{\text {cow }} / \alpha-\mathrm{L} \mathrm{A}_{\text {buffalo }}$ ratio for a high and low percentage of cow milk in buffalo milk, respectively. Others authors, such as Dal Bosco et al. (2018) and Muller et al. (2008), also exploited more than 1 marker or their ratio to screen the authenticity of milk. For their method, Dal Bosco et al. (2018) proposed using a combined quantification of $\beta$-carotene and ergocalciferol, specific for cow and buffalo milk, respectively, to detect cow milk. Muller et al. (2008) developed an algorithm based on the ratio of the sum of nonbovine $\beta$-LG (ovine or caprine) to the total $\beta$-LG in the milk mixtures. The use of only 1 protein as a marker of adulteration simplifies the entire process of analysis because it applies only one algorithm to derive the percentage of bovine milk eventually present in buffalo milk. It also reduces the time required to complete the $\mathrm{CE}$ procedure, from whey proteins separation to peak selection, and the probability of operators making mistakes in peak selection.

An important feature to consider when evaluating a calibration model is its predictive accuracy. To this end, the SEE and Sy.x were calculated using a series of 6 cow/buffalo mixtures (test set) prepared with cow and buffalo milk samples separate from those employed to prepare the training sets. We found that at a concentration of cow milk below $5.0 \%$, the SEE was $<7 \%$ whereas the Sy.x was $<5 \%$ (Table 4), supporting the good predictive accuracy of calibration model.

A possible concern in the development of a good calibration model is that the cow breed, and consequently breed-dependent genetic variations, could affect the total milk protein concentration or the milk protein variant content, such as the $\beta$-LGA and $\beta$-LGB ratio. The calibration model proposed here was generated using milk from different cow breeds (HolsteinFriesian, Italian Simmental, Jersey, Italian Brown, and cross-breeds), which permitted the inclusion of possible influences of breed on cow milk protein concentration in the calibration model. Moreover, having chosen cow $\alpha$-LA as the adulteration marker and not cow $\beta$-LG, in contrast to Muller et al. (2008) and Czerwenka et al. (2010), eliminated the interference of the different content of its 2 variants, $\mathrm{A}$ and $\mathrm{B}$, which affects the reliability of methods based on them.

The presence of $\alpha$-LA protein variants in a cattle population may introduce a degree of uncertainty in the reliability of our CE approach. However, only 4 protein variants have been described for $\alpha$-LA: $\alpha$-LA variant $\mathrm{B}$ is considered the reference protein and is pre- 
Table 2. Regression statistics for the standard set, with each set consisting of 17 samples of bovine/buffalo mixtures with increased cow whey percentage $(0,1,2.5,5,10,20,25,30,50,70,75,80,90,95,97.5,99$, and $100 \%)$

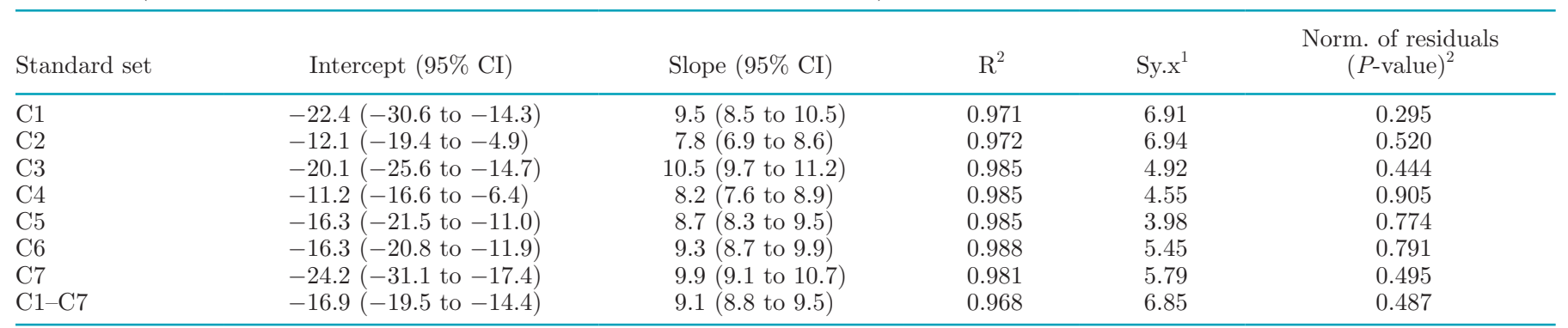

${ }^{1}$ Sy.x $=$ standard deviation of residuals.

${ }^{2}$ Normality of residuals was evaluated by Kolmogorov-Smirnov normality test.

Table 3. Repeatability and intermediate precision of cow $\alpha$-LA percentage area calculated on a test set of samples $(\mathrm{n}=4$ for each test set)

\begin{tabular}{|c|c|c|c|c|}
\hline \multirow[b]{2}{*}{ Item } & \multicolumn{4}{|c|}{ Test set (\% cow whey) } \\
\hline & $5 \%$ & $10 \%$ & $20 \%$ & $50 \%$ \\
\hline \multicolumn{5}{|l|}{ Repeatability } \\
\hline Mean \pm SD & $2.4 \pm 0.1$ & $3.2 \pm 0.1$ & $3.5 \pm 0.2$ & $7.0 \pm 0.2$ \\
\hline RSD $\%^{1}$ & 2.2 & 2.5 & 5.1 & 3.2 \\
\hline \multicolumn{5}{|c|}{ Intermediate precision } \\
\hline Mean \pm SD & $2.4 \pm 0.1$ & $3.1 \pm 0.1$ & $3.4 \pm 0.2$ & $6.9 \pm 0.1$ \\
\hline RSD \% & 2.1 & 1.8 & 4.4 & 1.2 \\
\hline
\end{tabular}

${ }^{1} \mathrm{RSD}=$ relative standard deviation.

dominant in Bos taurus, both variants A and B occur in Bos indicus cattle, and variant $\mathrm{C}$ is found only in Bos javanicus cattle (Farrell et al., 2004; Caroli et al., 2009). The variant $\mathrm{D}$ of $\alpha$-LA has only been described

Table 4. Predictive accuracy of the linear calibration function calculated on a test set of samples $(n=6$ for each test set)

\begin{tabular}{lrc}
\hline $\begin{array}{l}\text { Test set } \\
\text { \% cow whey) }\end{array}$ & SEE $^{1}$ & Sy.x \\
\hline 0 & 8.73 & 3.31 \\
1 & 7.54 & 4.88 \\
2.5 & 5.67 & 2.51 \\
5 & 6.89 & 1.41 \\
10 & 6.45 & 2.55 \\
20 & -0.15 & 3.08 \\
25 & 2.14 & 3.72 \\
30 & -1.19 & 4.85 \\
50 & -6.58 & 2.21 \\
70 & -4.73 & 4.62 \\
75 & -5.54 & 8.54 \\
80 & 0.89 & 9.38 \\
90 & -4.27 & 9.51 \\
95 & -2.39 & 10.76 \\
97.5 & 0.13 & 7.06 \\
99 & -3.66 & 5.68 \\
100 & -3.31 & 5.13
\end{tabular}

${ }^{1} \mathrm{SEE}=$ standard error of estimate; difference between the average estimated values of each replicate $(\mathrm{n}=6$ for each test set) and the reference value.

${ }^{2} \mathrm{Sy} \cdot \mathrm{x}=$ standard deviation of residuals. in Holstein-Friesian cows, with a very low frequency: 1 cow in 1,987 cows showed this variant in heterozygosis (Visker et al., 2012). In the Mediterranean buffalo, $\alpha-\mathrm{LA}$ variant $\mathrm{B}$ is the most frequent and $\alpha-\mathrm{LA}$ variant A has an extremely low allelic frequency (Chianese et al., 2004). Moreover, we tested our CE method on whey proteins obtained from bulk tank milk, thus minimizing the possible deleterious effects of genetic variants on reliability and robustness of our calibration curve. As shown in Figure 4, by comparing the electrophoretic profiles of whey proteins of the 4 cow breeds analyzed, we observed how the $\alpha$-LA peak of each cow breed has comparable electrophoretic mobility. This result is consistent with literature data (Farrell et al., 2004; Caroli et al., 2009) regarding the very high frequency of only $\alpha-\mathrm{LA}$ variant $\mathrm{B}$ in cows, endorsing the robustness and reliability of the $\mathrm{CE}$ approach proposed.

The CE approach described in this study has the great advantage of being an extremely fast and simple method to determine if milk adulteration occurs, compared with other methodologies proposed (Cartoni et al., 1999; Molina et al., 1999; Czerwenka et al., 2010; Dal Bosco et al., 2018). The procedure of CE analysis is fully automated, needing only loading a sample in instrument, and the time needed for electrophoretic separation on our CE system is very short (215 s). A limitation of our $\mathrm{CE}$ approach is the requirement of a 


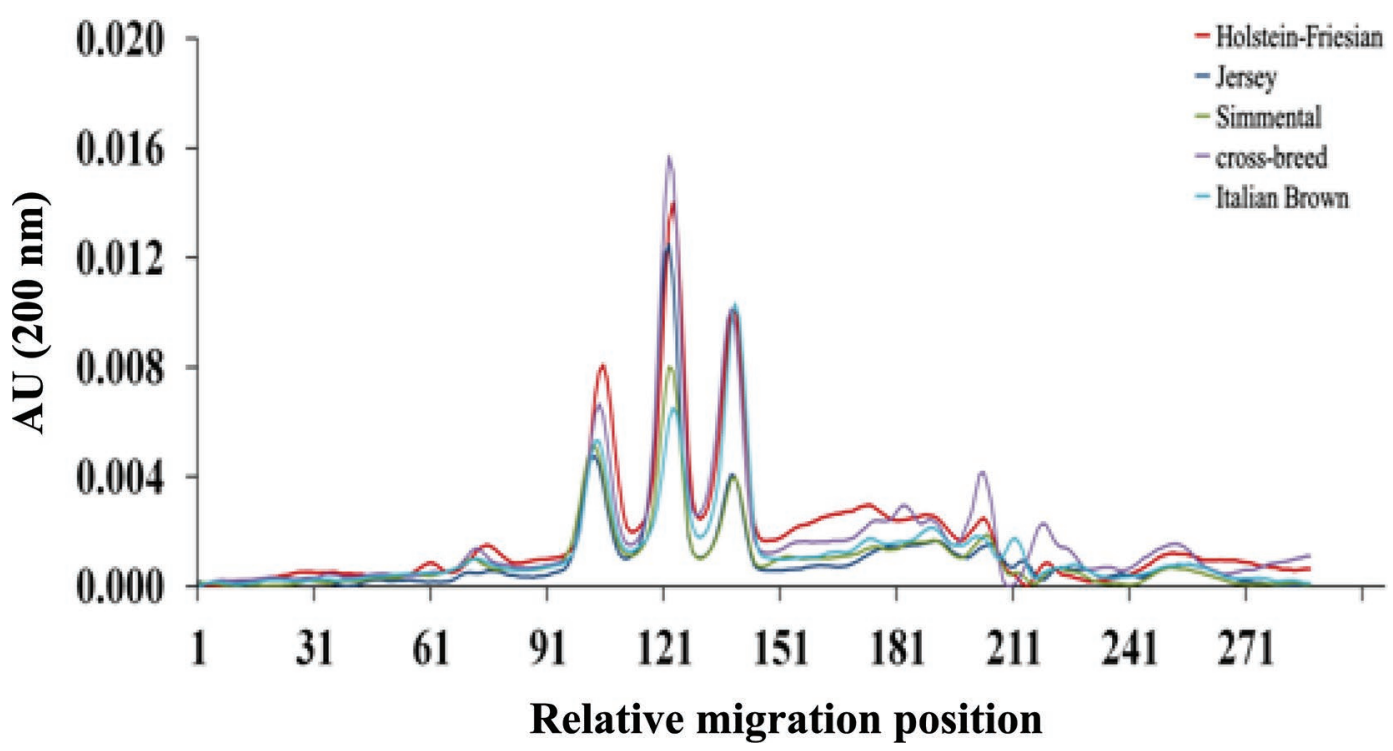

Figure 4. Whey protein capillary electrophoresis (CE) profiles of Holstein-Friesian (red line), Jersey (blue line), Simmental (green line), cross-breed (purple line), and Italian Brown (light blue) cows. AU = absorbance units.

calibration curve specific for each type of matrix analyzed, milk or cheese.

\section{CONCLUSIONS}

The CE method used in this work allowed the development of a robust and accurate calibration model that is able to identify if more abundant and cheaper cow milk has been fraudulently added to buffalo milk, using cow $\alpha-\mathrm{LA}$ as a marker for cow milk quantification. Therefore, given the results of the present study, we conclude that our CE strategy is particularly attractive as a rapid and reliable tool for identifying if adulteration with bovine milk has occurred during the production process of ewe or buffalo milk derivatives.

\section{ACKNOWLEDGMENTS}

This work was made possible thanks to provision of the instruments and financial contribution of the Interdepartment Services Centre of Veterinary for Human and Animal Health, University of Magna Graecia of Catanzaro, Italy.

\section{REFERENCES}

Borková, M., and J. Snášelová. 2005. Possibilities of different animal milk detection in milk and dairy products - A review. Czech J. Food Sci. 23:41-50.

Caira, S., G. Pinto, M. A. Nicolai, L. Chianese, and F. Addeo. 2016. Simultaneously tracing the geographical origin and presence of bovine milk in Italian water buffalo Mozzarella cheese using MALDI-TOF data of casein signature peptides. Anal. Bioanal. Chem. 408:5609-5621. https://doi.org/10.1007/s00216-016-9663-0.
Caroli, A. M., S. Chessa, and G. J. Erhardt. 2009. Invited review: Milk protein polymorphisms in cattle: Effect on animal breeding and human nutrition. J. Dairy Sci. 92:5335-5352. https://doi.org/10 $.3168 /$ jds.2009-2461.

Cartoni, G., F. Coccioli, R. Jasionowska, and M. Masci. 1999. Determination of cows' milk in goats' milk and cheese by capillary electrophoresis of the whey protein fractions. J. Chromatogr. A 846:135-141. https://doi.org/10.1016/S0021-9673(98)01032-2.

Cartoni, G. P., F. Coccioli, R. Jasionowska, and M. Masci. 1998. Determination of cow milk in ewe milk and cheese by capillary electrophoresis of the whey protein fractions. Ital. J. Food Sci. 10:317-328.

Cerquaglia, O., M. Sottocorno, L. Pellegrino, and M. Ingi. 2011. Detection of cow's milk, fat or whey in ewe and buffalo ricotta by HPLC determination of $\beta$-carotene. Ital. J. Food Sci. 23:367-372.

Chen, Q., X. Ke, J. S. Zhang, S. Y. Lai, F. Fang, W. M. Mo, and Y. P. Ren. 2016. Proteomics method to quantify the percentage of cow, goat, and sheep milks in raw materials for dairy products. J. Dairy Sci. 99:9483-9492. https://doi.org/10.3168/jds.2015-10739.

Chianese, L., S. Caira, S. Lilla, F. Pizzolongo, P. Ferranti, G. Pugliano, and F. Addeo. 2004. Primary structure of water buffalo $\alpha$-lactalbumin variants A and B. J. Dairy Res. 71:14-19. https:// doi.org/10.1017/S0022029903006551.

Czerwenka, C., L. Muller, and W. Lindner. 2010. Detection of the adulteration of water buffalo milk and mozzarella with cow's milk by liquid chromatography-mass spectrometry analysis of $\beta$-lactoglobulin variants. Food Chem. 122:901-908. https://doi .org/10.1016/j.foodchem.2010.03.034.

Dal Bosco, C., S. Panero, M. A. Navarra, P. Tomai, R. Curini, and A. Gentili. 2018. Screening and assessment of low molecular weight biomarkers of milk from cow and water buffalo: An alternative approach for the rapid identification of adulterated water buffalo mozzarellas. J. Agric. Food Chem. 66:5410-5417. https://doi.org/ 10.1021/acs.jafc.8b01270.

Dalmasso, A., T. Civera, F. La Neve, and M. T. Bottero. 2011. Simultaneous detection of cow and buffalo milk in mozzarella cheese by real-time PCR assay. Food Chem. 124:362-366. https://doi.org/10 .1016/j.foodchem.2010.06.017.

Di Domenico, M., M. Di Giuseppe, J. D. Wicochea Rodríguez, and C. Cammà. 2017. Validation of a fast real-time PCR method to detect fraud and mislabeling in milk and dairy products. J. Dairy Sci. 100:106-112. https://doi.org/10.3168/jds.2016-11695. 
Enne, G., D. Elez, F. Fondrini, I. Bonizzi, M. Feligini, and R. Aleandri. 2005. High-performance liquid chromatography of governing liquid to detect illegal bovine milk's addition in water buffalo Mozzarella: Comparison with results from raw milk and cheese matrix. J. Chromatogr. A 1094:169-174. https://doi.org/10.1016/j.chroma .2005.09.004

European Union. 2008a. Commission Regulation (EC) No 676/2008 of 16 July 2008 registering certain names in the Register of protected designations of origin and protected geographical indications. Off. J. L189:19-20.

European Union. 2008b. Commission Regulation (EC) No 273/2008 of 5 March 2008 laying down detailed rules for the application of Council Regulation (EC) No 1255/1999 as regards methods for the analysis and quality evaluation of milk and milk products. Off. J. L88:1-5.

Farrell, H. M. Jr., R. Jimenez-Flores, G. T. Bleck, E. M. Brown, J. E. Butler, L. K. Creamer, C. L. Hicks, C. M. Hollar, K. F. Ng-KwaiHang, and H. E. Swaisgood. 2004. Nomenclature of the proteins of cows' milk - Sixth revision. J. Dairy Sci. 87:1641-1674. https://doi .org/10.3168/jds.S0022-0302(04)73319-6.

Hazra, T., V. Sharma, R. Sharma, and S. Arora. 2017. A species specific simplex polymerase chain reaction-based approach for detection of goat tallow in heat clarified milk fat (ghee). Int. J. Food Prop. 20(Suppl. 1):S69-S75. https://doi.org/10.1080/10942912 .2017 .1289542

Lopreiato, V., C. Ceniti, F. Trimboli, E. Fratto, M. Marotta, D. Britti, and V. M. Morittu. 2017. Evaluation of the capillary electrophoresis method for measurement of immunoglobulin concentration in ewe colostrum. J. Dairy Sci. 100:6465-6469. https://doi.org/10 $.3168 /$ jds.2016-12284.
Molina, E., P. J. Martín-Álvarez, and M. Ramos. 1999. Analysis of cows', ewes' and goats' milk mixtures by capillary electrophoresis: Quantification by multivariate regression analysis. Int. Dairy J. 9:99-105. https://doi.org/10.1016/S0958-6946(99)00028-X.

Muller, L., P. Barták, P. Bednář, I. Fryšová, J. Ševčík, and K. Lemr. 2008. Capillary electrophoresis-mass spectrometry-A fast and reliable tool for the monitoring of milk adulteration. Electrophoresis 29:2088-2093. https://doi.org/10.1002/elps.200700794.

Rodriguez-Nogales, J. M. 2006. Approach to the quantification of milk mixtures by partial least-squares, principal component and multiple linear regression techniques. Food Chem. 98:782-789. https:/ /doi.org/10.1016/j.foodchem.2005.07.037.

Sassi, M., S. Arena, and A. Scaloni. 2015. MALDI-TOF-MS platform for integrated proteomic and peptidomic profiling of milk samples allows rapid detection of food adulterations. J. Agric. Food Chem. 63:6157-6171. https://doi.org/10.1021/acs.jafc.5b02384.

Trimboli, F., V. M. Morittu, C. Cicino, C. Palmieri, and D. Britti. 2017. Rapid capillary electrophoresis approach for the quantification of ewe milk adulteration with cow milk. J. Chromatogr. A. 1519:131-136. https://doi.org/10.1016/j.chroma.2017.08.075.

Visker, M. H. P. W., J. M. L. Heck, H. J. F. van Valenberg, J. A M. van Arendonk, and H. Bovenhuis. 2012. Short communication A new bovine milk-protein variant: $\alpha$-Lactalbumin variant $D$. J. Dairy Sci. 95:2165-2169. https://doi.org/10.3168/jds.2011-4794.

Zachar, P., M. Šoltés, R. Kasarda, J. Novotný, M. Novikmecová, an D. Marcinčáková. 2011. Analytical methods for the species identification of milk and milk products. Mljekarstvo 61:199-207. 